\title{
The low-crystallinity PVDF/PMMA/PEG/TiO 2 Type Polymer Diaphragm Prepared by Phase Inversion Method
}

\author{
Hong Gao, Mingpeng Mu, Zhongcai Shao, \\ School of Environment and Chemical Engineering, Shenyang Ligong University \\ *E-mail: $\underline{1641796109 @ q q . c o m}$
}

doi: $10.20964 / 2018.11 .29$

Received: 8 July 2018 / Accepted: 24 August 2018 / Published: 1 October 2018

\begin{abstract}
In order to improve the lithium ion battery of Poly-Vinylidene Fluoride (PVDF) conductivity and decrease crystallization of PVDF based polymer separator, introducing Poly-Methyl-Methacrylate (PMMA) and Poly-Vinylidene Fluoride (PVDF) to blend and doping organic additives PEG and inorganic nanomaterials $\mathrm{TiO}_{2}$. The PVDF/PMMA/PEG/TiO ${ }_{2}$ typed polymer diaphragm was prepared by Phase inversion method. Through the analysis of the porosity, ionic conductivity, charging and discharging to test, micro-morphology and electrochemical properties of the prepared $\mathrm{PVDF} / \mathrm{PMMA} / \mathrm{PEG} / \mathrm{TiO}_{2}$ porous separators, the optimum technological conditions for the preparation of the separator is polymer concentration of $8 \%$, PMMA of $30 \%$ and PEG of $30 \%$; the content of nanometer $\mathrm{TiO}_{2}$ is $5 \%$; the content of $\mathrm{C}_{2} \mathrm{H}_{5} \mathrm{OH}$ is $3 \%$; the reaction temperature is $45^{\circ} \mathrm{C}$, and the temperature is $30 \%$. Under the best scheme, the crystallinity of the prepared polymer diaphragm is lower than that of the pure PVDF diaphragm. The porosity of the polymer diaphragm is $81.5 \%$. The ionic conductivity is $5.2 \mathrm{mS} / \mathrm{cm}$, the tensile strength is $1183 \mathrm{~kg} / \mathrm{cm}^{2}$. The electrochemical stability window is $4.68 \mathrm{v}$, which is higher than $4.5 \mathrm{v}$. It can meet the normal working requirements of lithiumion batteries.
\end{abstract}

Keywords: polymer separator, phase inversion, low-crystallinity, nanomaterials, $\mathrm{TiO}_{2}$

\section{$\underline{\text { FULL TEXT }}$}

(C) 2018 The Authors. Published by ESG (www.electrochemsci.org). This article is an open access article distributed under the terms and conditions of the Creative Commons Attribution license (http://creativecommons.org/licenses/by/4.0/). 